Preprint, the final version, of the article that has been transferred to the journal's production team.

To cite this article: Ginzarly, M., \& Teller, J. (2020). Online communities and their contribution to local heritage knowledge. Journal of Cultural Heritage Management and Sustainable Development. DOI:

10.1108/JCHMSD-02-2020-0023

\title{
Online communities and their contribution to local heritage knowledge
}

\begin{abstract}
Purpose: The purpose of this study is to explore the potential of social media as a framework for people-centered heritage. With a focus on the interpretation and display of heritage by online communities, this paper aims at providing insights into the social production of heritage - the social co-construction of meanings of everyday landscape and the making of the collective and local identity.
\end{abstract}

Design/methodology/approach: This paper proposes a methodological roadmap for the digital ethnography of everyday heritage. It reveals (1) the fundamental principles according to which people make value judgments and associate meanings to the urban landscape, and (2) the role of online communities in conveying collective identity and heritage values within the community realm. As a case study area for the implementation of the proposed method, three Facebook community group pages for Tripoli, Lebanon were chosen. The posts and comments were translated into English and uploaded to NVivo 12 plus and a deductive thematic approach to qualitative data analysis was applied. The data was coded into three main nodes: the actors, the tangible assets, and the value registers.

Findings: Results show that Facebook users are concerned with environmental equality, common interests, utility, right to the city, and representativeness, while the beautification of heritage is often perceived as a threat to these values.

Originality/value: This investigation goes beyond heritage attributes (what) and values (why) to examine how values are assigned by local communities. It provides a comprehensive understanding of value judgment and the rationale and arguments used to justify positions and mobilize online community members in order to contribute to the digital co-construction of everyday heritage. 


\section{Introduction}

From the 1970s onward, the notion of cultural heritage was extended to go beyond authorized and designated aesthetic, monumental, and historical significance, that are dependent on the claims of experts and are institutionalized in cultural agencies, to consider heritage as a sociocultural construct subject to multiple perspectives from different stakeholders and to diverse associations of meanings that constantly change in space and across time (Taylor, 2016). These conceptualizations led to a holistic contextual view of urban heritage that questions the dichotomies of tangible, intangible, cultural, and natural forms of heritage and urge the application of a value-based landscape approach to heritage conservation (UNESCO, 2011; Fredheim \& Khalaf, 2016; Ginzarly, Houbart, \& Teller, 2019). A value-based approach to heritage is an attempt to extend the normative understanding of global cultural heritage and to move the World Heritage concept beyond Western thinking and value systems to consider different contexts and cultures and multiple expressions of cultural identity and communities' perceptions at different local, national, and regional levels (Smith \& Akagawa, 2009; Silberman, 2018). This approach has been accompanied by a growing interest in addressing heritage represented in everyday landscapes, daily practices, and shared experiences, and in developing frameworks and methods to assess and grasp diverse and conflicting cultural heritage values within local contexts (Stephenson, 2008; Heras et al., 2013; Ginzarly, Pereira Roders, \& Teller, 2019). Given that controversy, conflict, and cultural identity politics are inherent to heritage (Smith and Akagawa, 2009), the application of a value-based approach remains challenging, especially when the traditional lens of assessing the significance and the capability of the "language of heritage values" in capturing the full range of ways in which heritage is valued are questioned (Fredheim \& Khalaf, 2016, p. 469; Duval et al., 2019).

Further emphasis needs to be placed on civic engagement to facilitate intercultural dialogue between stakeholders with conflicting interests. Nevertheless, traditional participation tools and methods have resulted in a range of criticism stating that they are seldom mediated by groups with the most political power, leave both sides disappointed, and fail in achieving genuine participation in planning or other decisions (Arnstein, 1969; Swyngedouw, 2005). The new UNESCO Historic Urban Landscape Recommendation (HUL) encourages the use of information and communication technology, as an essential part of the knowledge of urban areas, to document and understand the 
complexity and fundamental components of cities and to communicate with all sectors of society to encourage public participation (UNESCO, 2011, p. 27). The HUL Recommendation provides a toolkit for the implementation of a value-based landscape approach to urban conservation and development, and it provides a guideline to its adaptation to local cultural contexts. So far, the HUL has been applied in different cities in developing countries to ensure urban sustainability (Heathcott, 2013; Rey-Pérez \& Pereira Roders, 2020).

Today, many scholars and cultural institutions have started to explore the potential use of digital technologies and social media in the context of participatory planning and public contribution to heritage websites, archives, online exhibitions, and museums (Giaccardi, 2012; Belenioti \& Vassiliadis, 2018). Governments have also gravitated to web-based participation mainly labeled as "e-government". Nevertheless, scholars argue that online platforms may reinforce hegemony and the Authorized Heritage Discourse depending on the kinds of the interaction through the point at which users are engaged as consumers and producers of content and on the space they provide for conflicting views to come together, pursuing a convergent or a crystallized view (Seltzer \& Mahmoudi, 2013; J. Taylor \& Gibson, 2017). This being said, grassroots initiatives appear as a platform to shape the dynamics of heritage production, foster civic engagement, and mediate conflicting interests in an urban context (Beeksma \& Cesari, 2019). The use of social media for crowdsourcing grassroots initiatives for the co-production of heritage knowledge and effective engagement in dialogues about cultural heritage conservation is, nonetheless, still very limited and not fully explored.

In line with this approach, and with the ultimate goal of better informing urban management, we explore the potential of social media as a framework for people-centered heritage. We propose a methodological road map to decipher the rationale behind value judgments at the heart of people's heritage concerns and the role of online communities in conveying collective identity and heritage values within the community realm. We address bottom-up platforms that are created by the public to claim an identity, articulate alternatives to dominant narratives of heritage, and challenge the official heritage discourse. Whilst building upon the public interpretation, display, and understanding of heritage, our methodological framework seeks to serve as a tool for further analysis of online communities that mediate the co-production of heritage knowledge. The framework is based on the concept of social production of heritage- the social co-construction of 
meanings of everyday landscape and the making of the collective and local identity. As a case study area for the implementation of the proposed method, three Facebook community group pages for Tripoli, Lebanon were chosen. The first is project-related (group 1), the second is more general and is related to projects and issues in the city (group 2), and the third is heritage-related (group 3).

To set the conceptual framework of this inquiry, we first address the current state of research in two themes emphasized by our research- heritage is a sociocultural construct, and social media is a platform for the digital co-construction of shared values and collective identities. Then, we present the research method for the study of online communities. We build upon a constructivist paradigm that is based on the study of hermeneutics to extract knowledge on the multiple social constructions of meaning. Subsequently, drawing on insights from the scholarly literature, we present the results of the analysis. We conclude with a critical reflection on the potential contribution of social media data to local heritage knowledge and heritage conservation and with recommendations for further research and policy changes.

\section{Conceptual Framework}

\subsection{The social construction of heritage: cultural values and meaning-making.}

Heritage is a form of social and cultural action (Byrne, 2007). The multiple processes of meaningmaking and the different meanings about a heritage asset come into conflict resulting in moments of re/construction and negotiation of cultural values, identity, place, and memory (Smith, 2006; Rodney Harrison, 2013). There is a contemporary imperative to consider different cultural values as equal and to encompass singular understandings of value to allow for plural interpretations and meaning (Gibson \& Pendlebury, 2009). Heritage values are socially constructed, context-driven, ambivalent, and dissonant (Gibson \& Pendlebury, 2009), and heritage is potentially "everywhere, for everyone, and we are all heritage experts" (Schofield, 2014, p. 2). In the book Uses of Heritage, Smith (2006) explored the different discourses of heritage- the official, legitimate, and authorized heritage discourse and the competing everyday and popular discourses- and the ways grassroots practices of cultural heritage contest and challenge bodies of expertise or dominant discourses.

Along with this scholarship, many scholars critically addressed Eurocentric value systems and heritage practice (Hamilakis \& Duke, 2007; Meskell, 2009, 2018; Waterton, 2010), and great 
attention was given to 'community-based' and consensus-building approaches, which de-center experts' authentication in the conservation process (Winter, 2013), and to local production and practices of heritage to build a sense of community and identity (Hall, 1999; Harrison, 2010). In the mid-2000s, the notion "co-production" gained ground and proposed an emancipatory solution to the authorized heritage discourse (Rex et al., 2016). In parallel, critical heritage studies have developed well-established methodologies for analyzing heritage discourses with a focus on contestation over the experts' and locals' interpretation of heritage values, conflict between authorized history and local historical knowledge, and differences between official conceptions of national identity (heritage by designation) and local identities related to everyday sociocultural constructs and experiences (heritage by appropriation) (De Cesari \& Herzfeld, 2015; Herzfeld, 2015; Beeksma \& De Cesari, 2019).

Controversy over heritage is nevertheless a constructive common ground that provides a space for raising alternative narratives about heritage, building a deeper knowledge and further appropriation of local heritage values, and formulating sustainable heritage management practices (Ginzarly, Farah, \& Teller, 2019). Pendlebury (2008) differentiated between heritage sites that are visited and experienced for the exceptional qualities as heritage and the other. The latter is experienced as part of everyday life and plays a major role in local identity construction and, in turn, connects to social inclusion, public values, and place-making (Pendlebury, 2008; Mosler, 2019). Urban spaces gain meaning through their functionality, everyday life, and experiences, contributing to defining the identity of a place and allowing the creation of everyday heritage that is spatially and socially interconnected with the urban context (Bollini, 2017; Mosler, 2019). Roe and Taylor (2014) note that everyday actions and building of meanings may construct what will be recognized as the cultural landscapes of tomorrow. Discussions about alternative visions of the meaning of the built environment are built upon varied arguments, and diverse modes of justifications are used to support different stakeholders' points of view (Marontate, 2013). Boltanski and Thévenot (2006) developed an analytical tool for studying processes through which groups with conflicting value systems resolve their disputes, and Heinich $(2011,2017)$ built on their framework to develop an axiology of cultural heritage, or in other words system of values, to study the fundamental values underpinning the criteria used to make value judgments and to negotiate the meaning of a cultural asset. 


\subsection{Social Media, shared values, and collective identity}

In the digital age, social media became a digital arena where members of virtual communities discuss meanings, construct shared values and collective identities, and generate alternative narratives to heritage (Silberman \& Purser, 2012; Gregory, 2015; Freeman, 2018). With over one billion monthly active members, Facebook is currently the third most visited website after Google and YouTube and the first most visited social network site in the world (Alexa Internet, 2018). Facebook allows users to initiate and join groups and community pages driven by shared values, common interests, or a collective cause/goal (Kent, Taylor, \& White, 2003; Vu, Abel, \& MorizetMahoudeaux, 2015). Social media platforms, such as Facebook, offer a means of challenging traditional perceptions of tangible and intangible heritage, and of exploring and articulating a community's socio-cultural relations with the physical setting, "thereby enabling a form of social production of heritage as the locus of our sense of place; that is, as 'the very matrix out of which human significance and meaning arise"” (Giaccardi \& Palen, 2008, p. 282). Facebook groups as a forum for discussion of the heritage of a particular place have popped up all over the world (Lewi et al., 2016). These groups mainly allow the organization of grassroots communities and their digital exchange, such as memories, historic photos, and often nostalgia for the past, with reactions to planning and building developments (Lewi et al., 2016). These grassroots initiatives are highly localized, generate new ways of engaging with heritage, and provide new prospects for digitallyenabled forms of heritage practice and non-experts perceptions of heritage (Giaccardi \& Palen, 2008; Caswell \& Mallick, 2014; Freeman, 2018).

Both groups and community pages allow users to post photos, links, wall posts, discussion boards, and videos and to share, like, and comment on posts. While some scholars refer to social media activism as clicktivism (Karpf, 2010), and question its contribution to enabling participative democracy and challenging dominant discourses and positions of power (Loader \& Mercea, 2011), social media optimists argue that storytelling, rhetoric, and the simple fact of being aware of social issues and willing to share narratives about them can all be considered as a form of activism and democratic engagement capable of enabling inclusion (Young, 2002; Kerwin, 2010). Based on this scholarship, Kavada (2015) developed a communication approach to explore the role of social media in creating the collective. Others have acknowledged the role of social media as organizing agents that allow the formation of connective action (Bennett \& Segerberg, 2012; Bennett, 
Segerberg, \& Walker, 2014). The cornerstone of connective action is the foundational element of sharing: the personalization that leads actions and content to be distributed widely across social networks" (Bennett \& Segerberg, 2012, p. 760). Against this backdrop, the participation in Facebook community pages and groups has been associated with community building and civic engagement as well as joint commitment (Valenzuela et al., 2009; Yuan et al., 2019).

Although the social media research is wide in scope, little consideration has been given to the use of Facebook in claiming heritage, building narratives about collective meaning, and discussing common development and conservation interests in this respect. Some researchers have stated that more studies are needed in examining people's digital engagement with heritage aside from institutional structures (King et al., 2016; van der Hoeven, 2018). Our study answers this call for more critical research on online communities and the digital construction of meanings and the production of heritage knowledge. Santana Talavera et al. (2012) analyzed discourses related to the cultural and natural heritage of Tenerife and Fuerteventura on Facebook to study the relevance of heritage in the shared images in connection with the potential tourists, the promoted heritage, and the differences among users concerning references to heritage assets in their discourses. Gregory (2015) analyzed a Facebook group concerned with the loss of heritage assets. She argued that Facebook enhances awareness of public attachment to the past and enables the development of an online community that can generate the needed social capital to mobilize against the destruction of heritage (Gregory, 2015). Bennett and Strong (2018) examined the capacity of save the place campaign to organize themselves into a cohesive movement through Facebook to preserve aspects of the local popular music heritage. The campaign came as a response to the closure of an iconic music venue to make way for a new hotel. Through Facebook, fans shared personalized memories of the Palace to eventually broaden the definition, nature, and function of popular music heritage (Bennett \& Strong, 2018). Marinelli and Andò (2018) analyzed the pragmatic use of Facebook by a social movement, Cinema America Occupato, as an expressive storytelling tool to activate structures of feelings, to collaboratively co-produce narratives about cultural heritage, and to reach and mobilize followers. Van der Hoeven (2018) analyzed 20 participatory heritage websites, including Facebook pages, to examine people's perception of heritage attributes and values and to demonstrate how online media can support people-oriented forms of urban heritage conservation. 
These studies show how Facebook enables bottom-up interpretations of everyday encounters with the physical environment that defy experts' definitions and understanding of heritage. In the following section, we present the applied method to frame the different value registers mobilized by Facebook users around everyday landscapes and heritage.

\section{Methodology}

To mitigate any ethical and privacy concerns, we contacted the administrators of the three Facebook groups before extracting the data. All the administrators permitted us to proceed with the analysis, and they even agreed to add one of the researchers as an administrator to allow access to the groups' insights and application programming interface (API). To extract the data from Facebook, we first created an Access Token, then we used RStudio software and the Rfacebook and Rcurl packages. We retrieved all the posts from 02-03-2015 to 15-03-2016 and their related comments, likes, shares, and date. This time frame is related to the date when group 1 was initiated to start a movement against the implementation of the Tall Parking Project that intends to build an underground parking garage in an Ottoman Square, and the date when the movement announced victory and the project was officially canceled. We decided to focus on this period because it provoked a debate between local activists and state actors about the right to the city, local heritage values, and civic engagement in decision making at the city level.

Since all the posts are in Arabic, we translated them into English before uploading the data to NVivo 12 plus to conduct the qualitative analysis. We applied a deductive thematic approach to qualitative data analysis. While qualitative analysis most commonly applies an inductive approach to thematic coding, many scholars have argued that qualitative analysis should not be undertaken to the exclusion of deductive reasoning and that generating categories from theory is appropriate and very useful for qualitative research (Patton, 2002; Braun \& Clarke, 2006; Berg \& Lune, 2012). Hence, our theory-driven codes borrowed from Heinich $(2011,2017)$ axiology of cultural heritage to address the fundamental principles according to which people make value judgments and associate meanings to the landscape. Heinich's framework allows a comprehensive understanding of the interplay of different evaluation criteria, and it is suitable for understanding how cultural heritage is valued, the rationales and arguments used to justify positions, and the processes through which consensus is reached (Marontate, 2013; Muriel, 2017). Accordingly, this framework allows a comprehensive understanding of value judgment, the co-construction of shared values, and the 
co-production of heritage knowledge. In her proposed framework, Heinich $(2011,2017)$ argues that value registers, meaning systems of values, are porous, influence one another, and do not have the same weight as (1) values do not stand on the same level; (2) some values are more easily combined than others in an argument; (3) some values, like rarity, are modulatory values that reinforce or weaken others as they may be negative or positive depending on their context; and (4) some values, like justice, can be mobilized in all contexts.

Accordingly, we coded the data into three main nodes: (1) the actors, meaning the subjects that are evaluating and that are involved in the discussion, whether passively or actively. This node subdivides into three subnodes that specify the local/municipal, national, and international level of actors involved; (2) the tangible assets that are evaluated, and here come four subnodes that vary from the district/neighborhood scale to the square, street, and building scale; and (3) the value registers (Heinich, 2017) and these are 11, including aesthetic (beauty), aesthesical (perceptive), hermeneutic (signification, meaning, interpretative activity, symbolism), civic (political, general interest, collective and public claims about common welfare, responsibility), juridical (framing of conflicts arrangement), economic, domestic (ancientness, familial belonging, confidence, care for transmission, protection), functional (utility, convenience, security), reputational, purificatory (authenticity, integrity, and ecology), and ethical (morality, justice). The following diagram summarizes the coding method applied in the qualitative data analysis (Fig. 1). Besides the analysis of Facebook data, we conducted face-to-face interviews with the Facebook groups' administrators to check if these groups are achieving their objectives and are succeeding in mobilizing community individuals or groups to take action on urban heritage and development issues. 
Figure 1. Deductive coding method

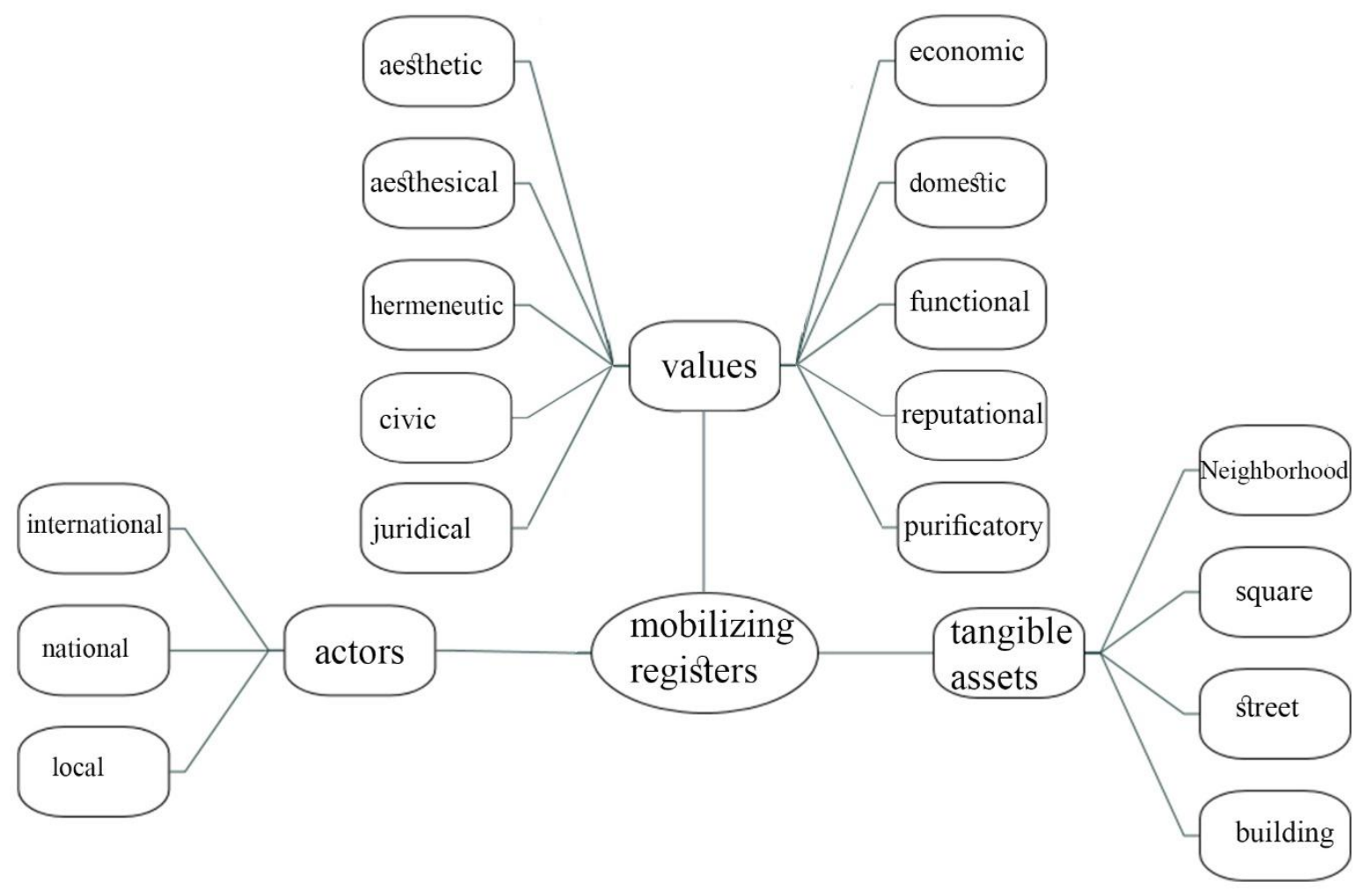

\section{The case study}

\subsection{Setting the context}

To set the background of every group, we will start with a brief description of the purpose of each group, then we will present a general reading of the qualitative analysis results. Group 1, has the objective of mobilizing different actors to stop the implementation of the Tall Parking Project in Tripoli; group 2 aims to present the views and ideas of those interested in the internal affairs of Tripoli, its issues, and development projects, with a presentation and critical analysis of these projects; and group 3 is devoted to sharing knowledge on Tripoli's heritage. Group 1 was initiated on 02-03-2015, group 2 on 30-05-2013, and group 3 on 14 -12-2012. As mentioned previously, we retrieved data from 02-03-2015 to 15-03-2016. Table 1 shows the corresponding number of posts posted on every group wall during this period and the related number of comments, likes, and shares. The demographic characteristics of the three groups have differences and similarities. Groups $1 \& 2$, which are projects-related, are dominated by men (60\% for group 1 and $67 \%$ for group 2), whereas group 3, which is heritage-related, has almost an equal representation among 
men and women. The majority of followers (70\%) in the three groups are young (between 18 and 44 years old). The three groups are dominated by local users.

Table 1. Number of analyzed posts for every group and related comments, likes, and shares.

\begin{tabular}{|l|l|l|l|l|}
\hline & $\mathrm{N}^{\circ}$ of posts & $\mathrm{N}^{\circ}$ of comments & $\mathrm{N}^{\circ}$ of likes & $\mathrm{N}^{\circ}$ of shares \\
\hline Group 1 & 205 & 458 & 7262 & 599 \\
\hline Group 2 & 91 & 727 & 5698 & 962 \\
\hline Group 3 & 278 & 408 & 8702 & 674 \\
\hline
\end{tabular}

While group 2 has the least number of followers and posts, its members are more active and engaged in discussions than the other two groups as it has a much higher number of comments and shares. Most probably because group 2 is more general in scope and presents critical discussions on urban projects, whereas group 3 celebrates the built cultural heritage of the city which explains the high number of likes, and group 1 is related to one specific project. A preliminary reading of the qualitative analysis results (Fig. 2) reveals that groups 1 and 2 mainly mobilize the civic register followed by the hermeneutic, functional, economic, and reputational registers associated with the different places in the city. Whereas group 3 is mainly concerned with built heritage assets and attributed hermeneutic, purificatory, and aesthetic registers. Results also show that the discussion is mainly occurring at the local and national level. 
Figure 2. Registers mobilized by the three online communities.

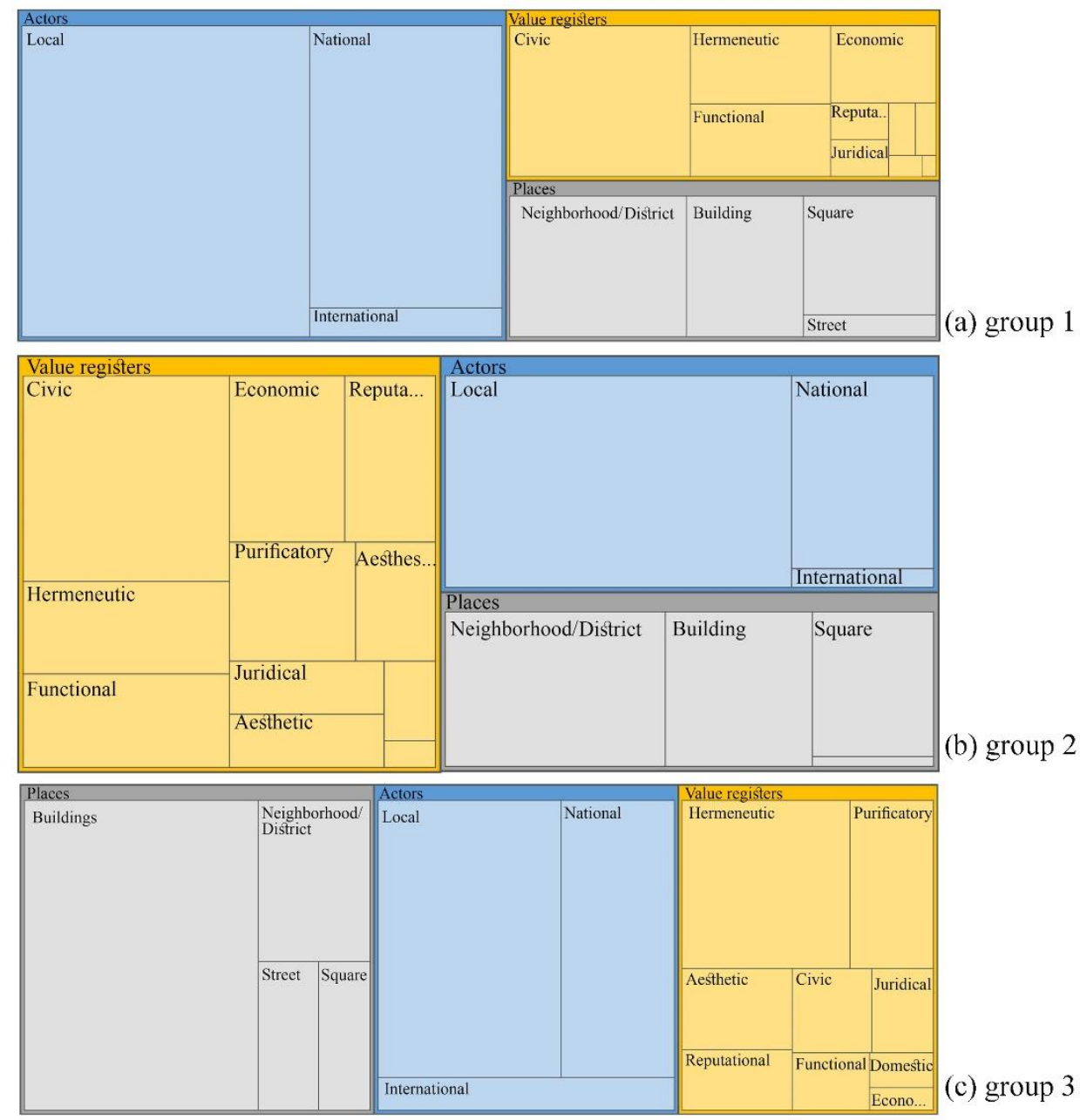

\subsection{Constructing everyday heritage}

The analysis of the three Facebook groups draws on the concepts introduced above. We address each of the most mobilized value registers separately keeping in mind that values are interchangeable, interrelated, and mutual. We do not aim to compare results from the three groups, neither to classify the multiple values of heritage. Instead, our objective is to place focus on the way values are ascribed through the lens of user-generated content that is tied to the locality and that reflects how users perceive and interact with everyday landscapes and construct narratives of local identity, local heritage, and social practices. So we will first address rationales used in arguments about alternative approaches to the definition and management of heritage. 
Within the civic register, the active members of the three Facebook groups address different issues, including-

(1) Claims about collective and common welfare, such as rights to inclusion and civic engagement in decision-making:

The center of Tripoli is the cultural property of its citizens and of the future generations, no one has the right to impose on the city a project that is rejected by the vast majority of the people of Tripoli.

(2) Calls to take action to stop the implementation of the Tall Parking Project; and

We invite everyone to support the people of Tripoli to defend their right to the city and go to sitin in Tall Square.

We have so far collected 1,160 votes rejecting the Tall Parking Project, we need 57 votes to reach our goal within 4 days.

(3) Discussions about common interests:

The Tall Parking Project was approved without studying its environmental impact and its impact on the urban and economic fabric [...] it is not assured that this project falls within the framework of sustainable development.

These posts constitute a form of digital activism of the sort discussed by Estrada-Grajales et al. (2018) to contest local development practices, to demand new dynamics of engagement in decision-making, and to call for the right to the city as city co-producers. The civic value is not expressed through narratives about the history of the city or about what is estimated as heritage, neither through conceptualizations related to visual aesthetics or authenticity. It is rather rooted in belonging, the common good, and the collective. In recent recommendations and conventions, heritage is endorsed as an apparatus for reinforcing not only local identity, but also democracy, engagement, and sustainable development (Council of Europe, 2005; UNESCO, 2011; De Cesari, 2017). So far this analysis has provided knowledge on how online communities construct local narratives of their concerns regarding the top-down approach to urban development driven by state and municipal authorities and their right to co-produce the city.

In addition to civic worth, Facebook users apply justifications based on the significance, meaning, and symbolism of different heritage assets. These justifications pertain to the hermeneutic register that, in our case, comes to-

(1) Acknowledge non-designated areas: 
The Mamluk core, which is 800 years old... and the Ottoman district, which is located in the vicinity of the Tall Square in Tripoli, are both urban heritage.

(2) Claim public ownership of cultural heritage:

The square is ours and its soil is of high value.

(3) Foster interpretative knowledge about the historic and socio-cultural values of heritage sites and built heritage assets; and

The Citadel of Tripoli, the largest war castle in Lebanon and the oldest, was founded by the Arab leader Sufyan bin Mujib al-Azdi in 636 AD.

(4) Discuss the demolition of heritage

Tripoli has been subject to a systematic campaign to destroy its heritage and architectural values that would have made it one of the most beautiful cities in the Mediterranean.

When the demolition of heritage buildings was completed, the loss occurred at the level of collective memory and the history of the city.

Digital platforms provide a space for self-expression and identity construction. The first two posts show how Facebook users assert ownership of a public square and challenge the limits of designated heritage to claim a non-designated site, the Ottoman district, as cultural heritage. Moreover, the discussion about the loss of heritage is linked to the loss of collective memory, and architectural and aesthetic values. Most relevant to this discussion is the dissonance theory of heritage and conflicts regarding local and national identity, heritage narratives, and heritage ownership (Graham et al., 2000; Harvey, 2001; Loulanski, 2006).

As for the functional register, it mainly appears with negative sentiments that are related to the neglect of many buildings and open spaces that led to the loss of their utility and to functions proposed by urban conservation and development projects:

Ironically, the project of reviving the cultural heritage of Tripoli ends up creating a platform above the course of Abu Ali River... The platform was designed to be a meeting place for the residents ... However, it was turned into a random and ugly market...

The train station- which became the rail of memories after it was stopped during the civil war to rust- is now merely used as a background for some bridal pictures for those who want to take footage in an archaeological place!

Even though functional values don't always contribute to regarding certain tangible attributes as heritage, the failure to recognize functional aspects of heritage can have catastrophic consequences, as it prevents the sustainable use of heritage and deprives heritage of its role within a sustainable social system (Szmelter, 2013; Fredheim \& Khalaf, 2016). The above posts show 
how the arguments are built upon negative expressions to express the loss of a value that is considered the most relevant in a specific context. Functions that are assigned to heritage assets are not always rooted in social preferences and are sometimes politicized as stakeholders assign different values to heritage based on their interests and expectations. When people (users) are mainly concerned with the social value of heritage, including spiritual, age, use, emotional, and entertainment values, decision-makers are more concerned with the political dimension of heritage, and professionals are primarily concerned with intrinsic value (Holden, 2006).

The economic register is articulated as people's prime concern and as a primary factor that should be given priority in development practices:

Priority is for developing a general guideline and a comprehensive development plan that addresses the crises of poverty, unemployment, and housing, and for projects that help to move the economic wheel.

The potential negative impact of the proposed garage is that it will not re-activate the economic role of the Tall area.

Development was not in terms of improving the image of the city, nor in terms of moving the economic wheel, commerce, and tourism, but on the contrary, some of the projects damaged the economy and the image of the city.

The first post shows that people's living conditions and daily socio-economic struggles are considered as main urban concerns. Arguments are not limited to the historic and aesthetic values. Instead, they take into consideration the social and economic reality of the city. Social and economic concerns and harsh living conditions provoke heritage tensions and conflicts around heritage and should not be overlooked (Joy, 2011). Moreover, poverty poses challenges to cultural heritage initiatives, because in poor cities in the Global South, heritage still didn't succeed in proving its significant contribution to socio-economic development (Ndoro, 2000; Arazi, 2014). In these contexts, in addition to performing cultural functions, heritage should also be called to contribute to the local economy, and economic activities should be integrated as heritage protection within the economic debate (Greffe, 1998). The economic value of heritage may conflict with the hermeneutic value of heritage creating an opposition between an "economic rationality" and a "cultural rationality" (Greffe, 1998).

As for the reputational register, it relates to honor, fame, and visibility (Heinich, 2017). In our case, this register appears with mixed emotions- 
(1) It celebrates the architects of certain projects because of their international recognition:

Tripoli's Fair is designed by the international architect Oscar Niemeyer, who designed the city of Brasilia, and it was considered a global engineering achievement.

(2) It rejects some projects because they are to be managed and implemented by a specific body, such as the Council of Development and Reconstruction (CDR); and

The CDR projects have been under implementation for years, and none of these projects has been completed. All the projects had so far blatant errors in design, specifications, and implementation.

We have all seen the catastrophic results of the cultural heritage project led by the CDR.

(3) It honors past achievements:

Hundreds of trades were scattered throughout Tripoli: carpentry, furnishings, soap, oil, copper works, and light metal products.

The Mamluk city that was once named Venice of the Middle East.

Reputation is a shared and a collective perception about an object, individual, or a place, and it is a core component of identity (Solove, 2007). Online platforms can be considered proxies of reputation and user-generated content can be seen as instances of reputation (Marchiori \& Cantoni, 2011). The heritage reputation construct is very complex. Monteiro et al. (2015) proposed a framework that first considers heritage characterization in space and time, then heritage values and beliefs and attitude towards heritage. Social media data can help to measure the heritage reputation and to obtain a public opinion regarding urban heritage practices and policies (Monteiro, Painho, \& Vaz, 2015). The above posts show that, in our case, the reputational register is rooted in the past and not projected into the present or future. It is more like nostalgia for the economic and functional roles the city played in the past and to famous local practices, like soap production. Users also refer to historic city nomenclature "Venice of the Middle East" and this could be understood as a community's interpretation of its past and previous city's image.

The purificatory register is mainly related to the authenticity and integrity of the city:

The soap Khan. Here began the story of the original soap industry, hundreds of years ago, to give the city a cultural identity.

Tripoli is the second Mamluk city after Cairo, it has a unique cultural heritage that is Lebanese, Arab and European.

A city of the Mamluk and Ottoman eras characterized by the combination of the East and the West in the architectural style and daily life practices ... Tripoli enjoys a privileged position between the hills ... the Mediterranean Sea, the islands, and the Cedar's Mountain. 
The above posts show that authenticity and integrity are expressed through tangible and intangible attributes and diverse cultural values. For instance, the first post relates the current soap khan to the historic origin of the soap manufacturing practices, and it identifies both tangible and intangible attributes as attempts to construct a local cultural identity. The second post expresses authenticity judgment through the age value of the city and its historicity that results in a complex layering of cultural heritage assets. This is also emphasized in the last post under this register, as it relates the past to the present considering cultural and natural landscape, daily practices, and diverse representations.

Finally, the Aesthetic register is related to-

(1) The architectural style of heritage; and

Al-Attar Mosque is founded by Badr al-Din Al-Attar in 1320, dating back to the Mamluk era. It has three doors, a marble pulpit, its minaret is the biggest and most beautiful in Tripoli.

(2) Conservation efforts that are reduced to the beautification of the historic environment:

Development from the approach of the Council for Development and Reconstruction is reduced to the application of "aesthetic cosmetics" on the facades of buildings.

As Heinich (2011) noted, the aesthetic register is far from being the central one governing the relationship to heritage, and this is what has been proved so far in this analysis as the requirement for meaning, common interest, and authenticity does not inevitably entail a requirement for beauty. This discussion leads us to the debate on scenic versus representative images of the city. It is clear so far in this analysis that people are more concerned about utility and representativeness than scenic beauty. Moreover, a beautification approach to urban conservation that mainly targets facades overlooking the main streets is very common in developing countries. These initiatives mainly seek to promote tourism activities and upgrade the economic condition of historic cores, but they have seldom led to disappointment and have not brought anticipated economic benefits (Sedky, 2005; Daher, 2007; Fan, 2014). The limitation of conservation to the physical improvement of listed buildings leads to "the production of a certain franchise of heritage and place" (Daher, 2007, p. 297) and modulates local heritage narratives, practices, and the use-value of heritage.

As Facebook users share their perceptions, views of what should be valued, and urban development and conservation concerns to public appraisal within the virtual community, they contribute to the co-construction of communally shared values and to the process of co-producing 
local knowledge. Our content analysis has, so far, provided insights into the different principles governing value judgment through the lens of user-generated content. Diverse social value lenses generate competing knowledge claims that can be managed through deliberative processes of knowledge co-production that extend interpretation from expert-only to a transdisciplinary community comprising specialists, decision-makers, and users (Strand, 2017; Kenter et al., 2019). In the following section, we will address the process through which values are negotiated within digital communities to provide insights into how the collective is built by investigating how some values are combined to reinforce one another or to stand up against or weaken other values.

\section{Discussion: Generating the collective}

We will discuss the results by looking at the entanglement of argumentative reasons, their elaboration, and development over time to see how online narratives, discussions, and interactions generate shared values and build the collective. It is worth to mention that the findings of this assessment are grounded in the locality of our case study and the specificities of the Facebook groups under investigation. Our specific findings must be tested against a variety of case studies conveying different heritage types and other social media platforms in multiple social configurations. This analysis provides a framework to identify the value registers that trigger more engagement. The proposed framework can be used to somehow ponder the value of an argument by looking at the number of likes, shares, and comments for every register. It can help to differentiate between positive and negative comments to infer emotions, motivations, and opinions in the assignment of values.

In group 1, 15 posts received more than 100 likes and 20 comments; they mobilize the civic (5 posts), the reputational ( 5 posts), functional ( 3 posts), aesthetic ( 1 post), and hermeneutic registers (1 post). Facebook-users used the online platform to invite the general public for joint meetings to bring efforts together and to sign a civil petition against the implementation of the Tall Project. The Photo of people signing the petition got 330 likes from posts and 660 likes in total (after being shared), 21 comments, and 23 shares. The comments were all positive and some of them asked for an electronic petition that was provided later on by the administrator. On the other hand, both the reputational and functional registers addressed here are associated with negative sentiments and are mainly based on criticism, incompetence of management authorities and 
planners, and failure of projects. Among the civic, reputational, and functional registers, we cannot calculate the total number of likes between these three registers because the first is much more apparent in posts than the second, so it will automatically get a higher number for total likes. So we cannot claim that one is on a higher level than the other. At the same time, For this Facebook group, the aesthetic, hermeneutic, and other registers fall behind the defense of common good, good practice, and the good adaptation of functions envisaged in projects proposals. Heinich (2017) argues that these registers are more adapted to shared values between users and enroll more actors. If the key is to shift from an individual to a collective framing of values (i.e. problematization), these registers are well adapted to this objective.

In the second group, 22 posts received more than 100 likes and 20 comments. The first post that got a high number of likes (284) discusses the different stories and meanings associated with Tall Square (hermeneutic register). The comments under this post (14) did not talk about personal experiences or personal values attributed to this place. Instead, they problematize national heritage and conservation practices. The next post defended the right to the city and to access the public space (civic register). The post received 199 likes and 46 comments. Some of the active users started to share narratives about similar personal experiences in the comment section:

It happened to me once. I told the officer this is my city and I have the right to take photos as much as I want.

Others objected or expressed negative sentiments regarding the situation:

By law, no one has the right to prevent us from taking photos.

It is a shame, they want to make our beautiful city so hard to see.

But this will affect tourism. Tourists like to take photos.

In this case, the civic register is connected to the juridical register. Both registers are efficient for mobilizing actors in the controversy as they are referring to everybody's rights. The third post with a high number of likes (481) and comments (68) criticized urban management in the city and the competence of state actors (reputational register). The comments were very varied in scope. Some called for independent locals to manage the city, as they are more aware of the city's need and more competent, others even added to the criticism, or expressed negative sentiments. The same day the group posted a map that shows the proposed Tal Project and provided a critical explanation of the project, its function, and spatial impact on the public square 
(functional register). This post received 64 comments. The comments turned into an interesting debate because the Secretary of the Board of Directors at the Council of Development and Construction commented:

I still do not understand why you are against the project. When the project is applied and when a private company manages it and the traffic problem is solved, you will all see that this project is for the benefit of the city.

In the comment section, the active users expressed concerns about inclusion and collaboration in decision-making processes and the loss of heritage as a result of urban development projects. Among the 22 posts with the most likes and comments, 6 are under the functional register, 5 are under the hermeneutic register, 4 are under the aesthetic, 4 are under the reputational, 2 are under the civic, and 1 is under the economic. So even though the civic register is the most mobilized one in the posts, it does not come on a higher level than the functional, hermeneutic, aesthetic, and reputational registers. In summary, the analysis of the interactions and individual commentary provided by this group showed how users share common narratives about everyday experiences and encounters with everyday landscapes, how users are concerned with common interests, environmental equality, and representativeness.

In group 3, the scope of the discussion is narrower. It mainly celebrates the architectural heritage of the city. Only 12 posts in this group have more than 100 likes. These posts display monuments, archeological remnants, or the interior of historic buildings, so they mainly celebrate the architectural and the visual (aesthetic register). Quite interestingly these posts generate less engagement from other members of the group, as they have at max 5 comments (Fig. 3). The posts with a high number of comments (more than 30) are the ones that display a photo followed by a question (Fig. 3), such as:

In which archeological site is this historic painting?

What is the use of these openings? And how do we call them?

Where was this historic alley?

Active Facebook users react with these types of posts and try to answer the questions and exchange knowledge by mainly mobilizing the purificatory register. 
Figure 3. . Left, photo with 100 likes; Right, photo with 121 comments.
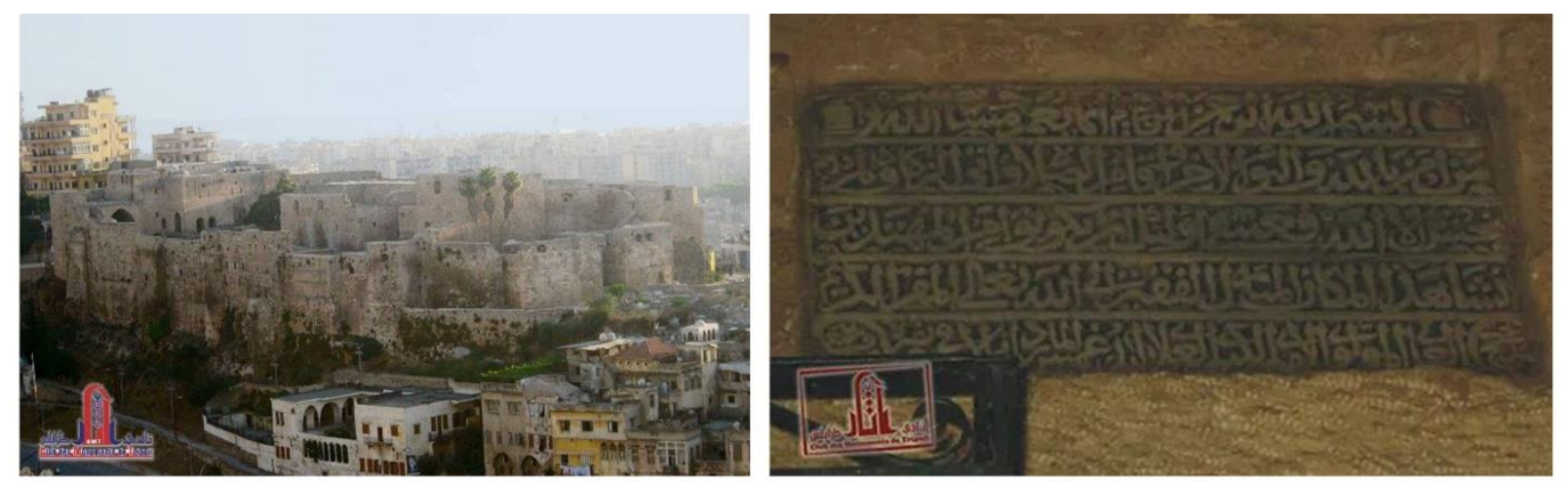

Based on our interviews with the administrators of these Facebook groups, group 1 played a significant role in mobilizing the civil society to take action against the implementation of the Tall Project and succeeded in moving the debate from the virtual space to the ground. Moreover, the administrator of group 2 informed us that the number of the group followers is increasing with time, and that the group is achieving its goal of spreading awareness about the importance of cultural heritage and the need to preserve it. He explained that the number of people that contact them through this group to be part of this movement and to participate in in-situ activities is also increasing with time. Whereas the online community of group 3 did not develop outside the digital world. The numeric representation of engagement (total number of likes, comments, and shares divided by number of posts) shows that the median of engagement is equal to 41 in group 1,81 in group 2, and 35 in group 3. So even though, group 3 has the most active members, this activism did not translate to in-situ local activism like the case of groups 1 and 2 that have a less total number of likes, comments, and shares.

\section{Conclusion}

There is a growing interest in conserving and managing the everyday heritage of local communities that defines local identities, place attachments, and sense of place (Timothy, 2011). Beyond designated heritage, everyday heritage may include daily practices, recreation and leisure activities, community sports, and places where people live and work. But how can the everyday heritage be identified? How are values ascribed to everyday landscape? And what is the rationale behind value-judgement? In this research, we mobilized a methodological framework for the digital ethnography of everyday heritage that builds upon a constructivist paradigm that is based on the study of hermeneutics to provide insights into the social constructions of meaning of 
everyday landscapes within a virtual community. This social construction is related to local knowledge narratives that are co-constructed by the concurrent participation of both narrative agents and active receivers. We argue that our method is transferable and can be employed to interpret data from different digital platforms. It can contribute to the current discourse on heritage by integrating different social media platforms and online applications in decision-making strategies as part of participatory governance. It can support learning about different groups' interests and cultural values, therefore facilitate the development of cultural heritage management plans and policies that balance concern for different stakeholders and deliver inclusive and sustainable development.

Analyzing the interactions within and between online communities provides a window to non-expert perceptions of heritage (Freeman 2018; Lewi et al. 2016). While a wide range of social media comes into play, the most frequently used platforms include Facebook, Instagram, Twitter, and Flickr. Each platform provides different digital data that vary from texts to photos, check-in, and geographical locations. Moreover, different platforms have different demographics of users. Although these data sources allow for new ways of interacting with and studying heritage sites, it is important to integrate different social media platforms and technologies to avoid biased generalization from social media users to the population from which they are drawn. Moreover, it is worth mentioning that technology may add a digital dimension to inequality for vulnerable population groups that do not have resources, skills, and education to procure the benefits of the information and communication technologies (Qureshi, 2014). Digital poverty prevents some social and economic groups from accessing, accumulating, and assimilating information; therefore, additional public policies need to be designed and implemented to convert the internet into a tool of citizenship that allows vulnerable groups to benefit from it and become participants in the digital age (Pedrozo, 2013).

Value-based assessments are usually built on three axes: the equal involvement of the different stakeholder groups (who), the adoption of a holistic approach to heritage considering exceptional and everyday heritage assets (what), and the application of an assessment method that considers the wide range of heritage values, including the social, ecological, economic, scientific, historic and so forth (why). The added value of the analysis of value registers is that it complements the model by allowing the specification of how values are assigned. Conflicting interpretations of 
heritage, resulting from attaching different weight to cultural values and different significances to the same heritage asset by stakeholder groups, raise alternative narratives and push the boundaries of the official heritage discourse. In this context, values become a means for bringing together large and diverse groups, including experts and locals, rather than an end of heritage conservation and management.

The temporal dimension remains central when assessing values; nevertheless, values seldom appear static through some categorization and evaluation exercises. The significance of social media for heritage management is that it allows the documentation of the construction process of values over time. Social media is a unique source of data in this regard, as it is much more comprehensive than other sources that were used beforehand, such as press and media, and it is more dynamic than ex-post interviews where values and value registers are somehow stabilized and their importance may witness a rationalization process. Moreover, social media is a source of valuable data in data-poor environments and it opens new possibilities for both heritage interpretation/characterization and conservation. 


\section{References}

Alexa Internet. (2018). Alexa Top 500 Global Sites. Retrieved February 5, 2019, from https://www.alexa.com/topsites

Arnstein, S. R. (1969). A Ladder Of Citizen Participation. Journal of the American Institute of Planners, 35(4), 216-224.

Beeksma, A., \& Cesari, C. D. (2019). Participatory heritage in a gentrifying neighbourhood: Amsterdam's Van Eesteren Museum as affective space of negotiations. International Journal of Heritage Studies, 25(9), 974-991.

Belenioti, Z., \& Vassiliadis, C. A. (2018). Museums \& Cultural Heritage via Social Media: An Integrated Literature Review. Tourismos, 12(3), 97-132.

Bennett, A., \& Strong, C. (2018). Popular Music Heritage, Grass-Roots Activism and Web 2.0: The Case of the 'Save the Palace' Campaign. Cultural Sociology, 12(3), 368-383.

Bennett, W. L., \& Segerberg, A. (2012). The Logic of Connective Action. Information, Communication \& Society, 15(5), 739-768.

Bennett, W. L., Segerberg, A., \& Walker, S. (2014). Organization in the crowd: Peer production in large-scale networked protests. Information, Communication \& Society, 17(2), 232260.

Berg, B. L., \& Lune, H. (2012). Qualitative research methods for the social sciences (8th ed). Boston: Pearson.

Bollini, L. (2017). The Urban Landscape and Its Social Representation. A Cognitive Research Approach to Rethinking Historical Cultural Identities. In G. Amoruso (Ed.), Putting Tradition into Practice: Heritage, Place and Design: Proceedings of 5th INTBAU International Annual Event (Vol. 3, pp. 834-842). Springer, Cham.

Boltanski, L., \& Thévenot, L. (2006). On Justification: Economies of Worth. Princeton University Press.

Braun, V., \& Clarke, V. (2006). Using thematic analysis in psychology. Qualitative Research in Psychology, 3(2), 77-101.

Byrne, D. R. (2007). Heritage as social action. In G. Fairclough, R. Harrison, J. Schofield, \& J. J. H. Jameson (Eds.), The Heritage Reader (1 edition, pp. 149-173). New York: Routledge.

Caswell, M., \& Mallick, S. (2014). Collecting the easily missed stories: Digital participatory microhistory and the South Asian American Digital Archive. Archives and Manuscripts, $42(1), 73-86$.

Council of Europe. (2005). Convention on the Value of Cultural Heritage for Society (Faro Convention). Retrieved from https://www.coe.int/en/web/culture-and-heritage/faroconvention

Daher, R. F. (2007). Tourism, Heritage, and Urban Transformations in Jordan and Lebanon: Emerging Actors and Global-Local Juxtapositions. In R. F. Daher (Ed.), Tourism in the Middle East: Continuity, change, and transformation (pp. 263-307). Clevedon; Buffalo: Channel View Publications.

De Cesari, C., \& Herzfeld, M. (2015). Urban Heritage and Social Movements. In L Meskell (Ed.), Global heritage: A reader (pp. 171-195).

De Cesari, Chiara. (2017). Thinking Through Heritage Regimes. In R. F. Bendix, A. Eggert, \& A. Peselmann (Eds.), Heritage Regimes and the State (pp. 399-413).

Duval, M., Smith, B., Hœrlé, S., Bovet, L., Khumalo, N., \& Bhengu, L. (2019). Towards a holistic approach to heritage values: A multidisciplinary and cosmopolitan approach. International Journal of Heritage Studies, O(0), 1-23. 
Estrada-Grajales, C., Foth, M., \& Mitchell, P. (2018). Urban imaginaries of co-creating the city: Local activism meets citizen peer-production. Journal of Peer Production.

Fan, L. (2014). International influence and local response: Understanding community involvement in urban heritage conservation in China. International Journal of Heritage Studies, 20(6), 651-662.

Fredheim, L. H., \& Khalaf, M. (2016). The significance of values: Heritage value typologies reexamined. International Journal of Heritage Studies, 22(6), 466-481.

Freeman, C. G. (2018). Participatory Culture and the Social Value of an Architectural Icon: Sydney Opera House. Routledge.

Giaccardi, E. (2012). Heritage and Social Media: Understanding Heritage in a Participatory Culture. Routledge.

Giaccardi, E., \& Palen, L. (2008). The Social Production of Heritage through Cross-media Interaction: Making Place for Place-making. International Journal of Heritage Studies, 14(3), 281-297.

Gibson, L., \& Pendlebury, J. (2009). Introduction. In L. Gibson \& J. Pendlebury (Eds.), Valuing Historic Environments (1 edition, pp. 1-18). Farnham, Surrey ; Burlington, VT: Routledge.

Ginzarly, M., Farah, J., \& Teller, J. (2019). Claiming a role for controversies in the framing of local heritage values. Habitat International, 88, 101982.

Ginzarly, M., Pereira Roders, A., \& Teller, J. (2019). Mapping historic urban landscape values through social media. Journal of Cultural Heritage, 36, 1-11.

Ginzarly, M., Houbart, C., \& Teller, J. (2019). The Historic Urban Landscape approach to urban management: A systematic review. International Journal of Heritage Studies, 25(10), 999-1019.

Graham, B. J., Ashworth, G. J., \& Tunbridge, J. E. (2000). A geography of heritage: Power, culture, and economy. London : New York: Arnold ; Oxford University Press.

Gregory, J. (2015). Connecting with the past through social media: The 'Beautiful buildings and cool places Perth has lost' Facebook group. International Journal of Heritage Studies, 21(1), 22-45.

Hall, S. (1999). Un-settling 'the heritage', re-imagining the post-nationWhose heritage? Third Text, 13(49), 3-13.

Hamilakis, Y., \& Duke, P. (2007). ARCHAEOLOGY AND CAPITALISM: FROM ETHICS TO POLITICS. Left Coast Press.

Harrison, R. (2010). Heritage as Social Action. In S. West (Ed.), Understanding heritage in practice (pp. 240-276). Retrieved from http://discovery.ucl.ac.uk/1359126/

Harrison, Rodney. (2013). Heritage: Critical Approaches. Routledge.

Harvey, D. C. (2001). Heritage Pasts and Heritage Presents: Temporality, meaning and the scope of heritage studies. International Journal of Heritage Studies, 7(4), 319-338.

Heathcott, J. (2013). Historic Urban Landscapes of the Swahili Coast: New Frameworks for Conservation. In R. van Oers \& S. Haraguchi, (Eds.), Swahili historic urban landscapes (pp. 20-39). Paris, France: UNESCO.

Heinich, N. (2011). The Making of Cultural Heritage. The Nordic Journal of Aesthetics, 22(4041).

Heinich, N. (2017). Des valeurs: Une approche sociologique. Paris: Editions Gallimard.

Heras, V. C., Wijffels, A., Cardoso, F., Vandesande, A., Santana, M., Orshoven, J. V., ... Balen, K. van. (2013). A value-based monitoring system to support heritage conservation 
planning. Journal of Cultural Heritage Management and Sustainable Development, 3(2), $130-147$.

Herzfeld, M. (2015). Heritage and the Right to the City: When Securing the Past Creates Insecurity in the Present. Heritage \& Society, 8(1), 3-23.

Holden, J. (2006). Cultural Value and the Crisis of Legitimacy: Why Culture Needs a Democratic Mandate. Demos.

Joy, C. (2011). The Politics of Heritage Management in Mali: From UNESCO to Djenné. Left Coast Press.

Karpf, D. (2010). Online Political Mobilization from the Advocacy Group's Perspective: Looking Beyond Clicktivism. Policy \& Internet, 2(4), 7-41.

Kaul, A. (2011). The village that wasn't there: Appropriation, domination, and resistance. In V. Strang \& M. Busse (Eds.), Ownership and Appropriation (pp. 239-259). Bloomsbury Publishing.

Kavada, A. (2015). Creating the collective: Social media, the Occupy Movement and its constitution as a collective actor. Information, Communication \& Society, 18(8), 872886.

Kent, M. L., Taylor, M., \& White, W. J. (2003). The relationship between Web site design and organizational responsiveness to stakeholders. Public Relations Review, 29(1), 63-77.

Kenter, J. O., Raymond, C. M., van Riper, C. J., Azzopardi, E., Brear, M. R., Calcagni, F., ... Thankappan, S. (2019). Loving the mess: Navigating diversity and conflict in social values for sustainability. Sustainability Science, 14(5), 1439-1461.

Kerwin, A. M. (2010). How to Get the Social-Media Generation Behind Your Cause (pp. 81, (26), 8). Retrieved from Advertising Age website: https://adage.com/article/digital/socialmedia-generation/144686/

King, L., Stark, J. F., \& Cooke, P. (2016). Experiencing the Digital World: The Cultural Value of Digital Engagement with Heritage. Heritage \& Society, 9(1), 76-101.

Lewi, H., Smith, W., Murray, A., \& Cooke, S. (2016). Visitor, contributor and conversationalist: Multiple digital identities of the heritage citizen. Historic Environment, 28(2), 12.

Loader, B. D., \& Mercea, D. (2011). NETWORKING DEMOCRACY?: Social media innovations and participatory politics. Information, Communication \& Society, 14(6), $757-769$.

Loulanski, T. (2006). Revising the Concept for Cultural Heritage: The Argument for a Functional Approach. International Journal of Cultural Property, 13(2), 207-233.

Marchiori, E., \& Cantoni, L. (2011). The Online Reputation Construct: Does it Matter for the Tourism Domain? A Literature Review on Destinations' Online Reputation [Text].

Marinelli, A., \& Andò, R. (2018). Collective action and affective publics: The "cinema America occupato" storytelling on facebook. Comunicazioni Sociali, 2018(2), 278-297. Retrieved from Scopus.

Marontate, J. (2013). Strategies for Studying Multiple Meanings in Conservation Research. CeROArt. Conservation, exposition, Restauration d'Objets d'Art, (HS).

Meskell, Lynn (Ed.). (2009). Cosmopolitan archaeologies. Durham, NC: Duke University Press.

Meskell, Lynn. (2018). A Future in Ruins: UNESCO, World Heritage, and the Dream of Peace. Oxford, New York: Oxford University Press.

Monteiro, V., Painho, M., \& Vaz, E. (2015). Is the heritage really important? A theoretical framework for heritage reputation using citizen sensing. Habitat International, 45, Part $2,156-162$. 
Mosler, S. (2019). Everyday heritage concept as an approach to place-making process in the urban landscape. Journal of Urban Design, 24(5), 778-793.

Muriel, D. (2017). The Network of Experts and the Construction of Cultural Heritage. Identity Formation in Contemporaneity. TECNOSCIENZA: Italian Journal of Science \& Technology Studies, 8(1), 23-50-50.

Patton, M. Q. (2002). Qualitative Research \& Evaluation Methods. SAGE.

Pedrozo, S. (2013). New Media Use in Brazil: Digital Inclusion or Digital Divide? Online Journal of Communication and Media Technologies, 3(1).

Pendlebury, J. (2008). Conservation in the Age of Consensus. Routledge.

Qureshi, S. (2014). Overcoming Technological Determinism in Understanding the Digital Divide: Where Do We Go From Here? Information Technology for Development, 20(3), 215-217. https://doi.org/10.1080/02681102.2014.930981

Rex, B., lioyd, K., \& Morse, N. (2016). Co-Production in Heritage: Towards New Imaginaries. Part II. Co-Production, Conservation and Memory; Co-Production and the Professional Imaginary. Presented at the Concordia, John Molson School of Business . Retrieved from https://sites.grenadine.co/sites/patrimoine/en/ACHS2016/items/292

Rey-Pérez, J., \& Pereira Roders, A. (2020). Historic urban landscape: A systematic review, eight years after the adoption of the HUL approach. Journal of Cultural Heritage Management and Sustainable Development, ahead-of-print.

Roe, M., \& Taylor, K. (2014). New Cultural Landscapes: Emerging issues, concepts, and themes. In M. Roe \& K. Taylor (Eds.), New Cultural Landscapes (pp. 1-23). London ; New York: Routledge.

Santana Talavera, A., Rodríguez Darias, A. J., Díaz Rodríguez, P., \& Aguilera Ávila, L. (2012). Facebook, heritage and tourism reorientation. The cases of Tenerife and Fuerteventura (Canary Isles, Spain). International Journal of Web Based Communities, 8(1), 24-39.

Schofield, J. (Ed.). (2014). Who Needs Experts?: Counter-mapping Cultural Heritage (1 edition). Farnham, Surry, UK ; Burlington, VT: Routledge.

Sedky, A. (2005). The politics of area conservation in Cairo. International Journal of Heritage Studies, 11(2), 113-130.

Seltzer, E., \& Mahmoudi, D. (2013). Citizen Participation, Open Innovation, and Crowdsourcing: Challenges and Opportunities for Planning. Journal of Planning Literature, 28(1), 3-18.

Silberman, N. (2018). Heritage interpretation and human rights. In S. Watson, A. J. Barnes, \& K. Bunning (Eds.), A Museum Studies Approach to Heritage. Routledge.

Silberman, N., \& Purser, M. (2012). Collective Memory as Affirmation: People-Centered Cultural Heritage in a Digital Age. In Heritage and Social Media: Understanding heritage in a participatory culture, Elisa Giaccardi, ed. (pp. 13-39).

Smith, L. (2006). Uses of Heritage. Routledge.

Smith, L., \& Akagawa, N. (2009). Introduction. In L. Smith \& N. Akagawa (Eds.), Intangible heritage (pp. 1-9).

Solove, D. J. (2007). The Future of Reputation: Gossip, Rumor, and Privacy on the Internet (SSRN Scholarly Paper No. ID 2899125). Retrieved from Social Science Research Network website: https://papers.ssrn.com/abstract=2899125

Stephenson, J. (2008). The Cultural Values Model: An integrated approach to values in landscapes. Landscape and Urban Planning, 84(2), 127-139. 
Strand, R. (2017). Post-Normal Science. In Routledge Handbook of Ecological Economics (pp. 288-298).

Swyngedouw, E. (2005). Governance Innovation and the Citizen: The Janus Face of Governance-beyond-the-State. Urban Studies, 42(11), 1991-2006.

Szmelter, I. (2013). New Values of Cultural Heritage and the Need for a New Paradigm Regarding its Care. CeROArt. Conservation, exposition, Restauration d'Objets d'Art, (HS).

Taylor, J., \& Gibson, L. K. (2017). Digitisation, digital interaction and social media: Embedded barriers to democratic heritage. International Journal of Heritage Studies, 23(5), 408420.

Taylor, K. (2016). The Historic Urban Landscape paradigm and cities as cultural landscapes. Challenging orthodoxy in urban conservation. Landscape Research, 41(4), 471-480.

Timothy, D. J. (2011). Cultural Heritage and Tourism. In Cultural Heritage and Tourism: An Introduction. Channel View Publications.

UNESCO. (2011). Recommendation on the historic urban landscape. UNESCO World Heritage Centre, Paris.

Valenzuela, S., Park, N., \& Kee, K. F. (2009). Is There Social Capital in a Social Network Site?: Facebook Use and College Students' Life Satisfaction, Trust, and Participation1. Journal of Computer-Mediated Communication, 14(4), 875-901.

van der Hoeven, A. (2018). Valuing Urban Heritage Through Participatory Heritage Websites: Citizen Perceptions of Historic Urban Landscapes. Space and Culture, 1-20.

Vu, X. T., Abel, M.-H., \& Morizet-Mahoudeaux, P. (2015). A user-centered and group-based approach for social data filtering and sharing. Computers in Human Behavior, 51, 10121023.

Waterton, E. (2010). Politics, policy and the discourses of heritage in Britain. Basingstoke: Palgrave Macmillan.

Winter, T. (2013). Clarifying the critical in critical heritage studies. International Journal of Heritage Studies, 19(6), 532-545.

Young, I. M. (2002). Inclusion and Democracy. Oxford University Press.

Yuan, E., Feng, M., \& Liu, X. (2019). The R/evolution of civic engagement: An exploratory network analysis of the Facebook groups of occupy Chicago. Information, Communication \& Society, 22(2), 267-285. 